\title{
Pituitary apoplexy masquerading as bacterial meningitis
}

\author{
Angela N. Paisley MD, Akheel A. Syed PhD
}
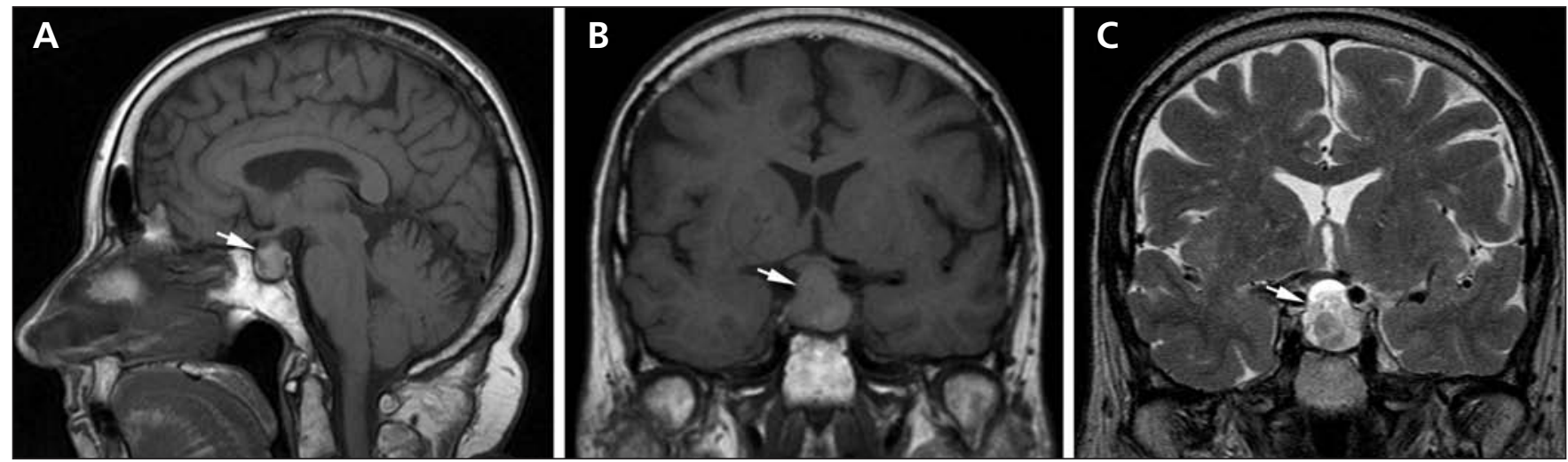

Figure 1: Magnetic resonance images (MRIs) showing sub-acute pituitary apoplexy (arrows). The enlarged pituitary (A; sagittal $t_{1-}$ weighted image) abutted on cavernous vessels and optic chiasm (B; coronal $t_{1}$-weighted image), and there were heterogeneous foci of hyper- and hypo-intensity ( $C_{;}$coronal $t_{2}$-weighted image). The signal changes on MRI result from degradation of hemoglobin.

Competing interests: None declared.

This article has been peer reviewed.

Affiliations: From the Department of

Endocrinology and General (Internal) Medicine (Paisley, Syed), Salford Royal NHS Foundation Trust and University Teaching Hospital, Salford, Greater Manchester, UK; and the University of Manchester (Syed), Manchester, UK.

Correspondence to: Akheel Syed, aas@drsyed.org

CMAJ 2012. DOI:10.1503 /cmaj.120174
$\Lambda$ 67-year-old woman with treated hypertension presented with headache, vomiting, light sensitivity and partial loss of vision. On examination, she had a temperature of $38.4^{\circ} \mathrm{C}$ and left temporal hemianopia. Her examination was otherwise unremarkable. Investigations showed a C-reactive protein level of 295 (normal $0-10) \mathrm{mg} / \mathrm{L}$ and a leukocyte count of 16100 (normal 4000-11 000) per $\mathrm{mm}^{3}$ in her blood. Computed tomography (CT) of her head was normal. Analysis of her cerebrospinal fluid (CSF) showed a leukocyte count of $908 / \mathrm{mm}^{3}$ (90\% polymorphs), an erythrocyte count of $124 / \mathrm{mm}^{3}$ and a protein level of 1.19 (normal 0.10-0.40) g/L. She was given broad-spectrum antibiotics for presumed bacterial meningitis. Cultures of the CSF were sterile. The results of autoantibody studies and polymerase chain reactions for meningococcus, varicella-zoster and herpes simplex were negative.

Nine days after the CT scans were obtained, magnetic resonance imaging (MRI) showed subacute pituitary apoplexy (i.e., bleeding; Figure 1). The patient's basal pituitary profile was normal, with the exception of hypogonadism. Because serial MRIs showed increases in the size of the lesion, and perimetry showed persistent left temporal hemianopia, endoscopic decompression of the pituitary was performed. Histology confirmed apoplexy. Postoperatively, the patient's visual fields normalized. She was given hydrocortisone and growth hormone for partial hypopituitarism.

Pituitary adenomas have an estimated worldwide prevalence of up to $17 \%$; however, classic pituitary apoplexy is uncommon, with a reported incidence of $0.5 \%-10 \%$ in patients who have undergone surgery for pituitary adenoma. ${ }^{1}$ It is characterized by the sudden onset of a life-threatening neuro-ophthalmologic syndrome from hemorrhagic infarction of a pituitary adenoma. ${ }^{1}$ Risk factors include hypertension, anticoagulant and dopamine-agonist therapies, dynamic pituitary testing and major surgery.

Magnetic resonance imaging is superior to CT for diagnosing pituitary apoplexy (sensitivity: $91 \%$ v. $28 \%$, respectively ${ }^{2}$ ). Pituitary apoplexy can produce a sterile, irritant chemical meningitis that mimics bacterial meningitis from release of debris into the $\mathrm{CSF}^{3}$ and it should be considered for anyone who presents with neuro-ophthalmologic features in this setting, even if the findings of cerebral CT are normal. Endocrine monitoring is essential, because most patients will experience some form of hypopituitarism in the long term.

\section{References}

1. Nawar RN, AbdelMannan D, Selman WR, et al. Pituitary tumor apoplexy: a review. J Intensive Care Med 2008;23:75-90.

2. Sibal L, Ball SG, Connolly V, et al. Pituitary apoplexy: a review of clinical presentation, management and outcome in 45 cases. Pituitary 2004;7:157-63.

3. Brouns R, Crols R, Engelborghs S, et al. Pituitary apoplexy presenting as chemical meningitis. Lancet 2004;364:502. 